\title{
Charakter Variable Model Determination of Regional Potential Decisions using Driven Data
}

\author{
Taufiq, Herman Mawenkang, M. Zarlis, Saib Suwilo
}

\begin{abstract}
Regional potential is an ability that exists in an area that can be developed and is able to provide benefits to the people of the area which includes agriculture, plantation and fisheries. Regional potential is also a supporter of the national economy and optimal management planning is needed. The problem that arises in regional potential management planning is that the data to be processed is large-scale data and there is uncertainty. To overcome this problem, Data Driven is needed so that the Charakter Variable Model is Determined for Decision of Regional Potential Using Data Driven Case Study of Bireuen District, Aceh Province, July District. The desire to improve human decision making motivates the development of various modeling tools in economic disciplines, operations research, decision theory, decision analysis, and statistics. In each of these modeling tools, knowledge of a system is represented by algebraic, logical or statistical variables. Interactions between these variables are expressed by logical equations or rules, which may be enhanced by explicit representations of uncertainty, such as air, the state of natural potential.
\end{abstract}

Keywords : Regional Potential, Data Driven, Decision, Varchar.

\section{INTRODUCTION}

\subsection{Background}

The potential of a region is a map of capabilities that exist in an area that can be developed and able to benefit the people of the area and can be used as a supporter of the national economy. This understanding gives the connotation that optimal management planning is needed in order to achieve the intended expectations. The regional potential which is the focus of the study in this dissertation is the potential derived from natural resources, namely in the fields of agriculture, plantations and fisheries.

In a literature study the use of Decision Support Systems related to regional potential planning is more aimed at land use planning, because this activity also includes spatial optimization, namely optimal settings for identifying the best locations of natural resources (Tong and Murray, 2012; Ligman -Zielinska, 2017). In the construction of a Decision Support System Model for regional potential it is important to know which areas there are strengths that affect the potential market attractiveness of the Aceh region (Case).

Revised Manuscript Received on October 15, 2019.

* Correspondence Author

Taufiq, USU \&camp.TI S3 Student and Lectures in Electrical Engenering. Malikusaleh University.

Herman Mawenkang, Faculty of Computer and IT Sciences, University of Sumatera Indonesia

M. Zarlis, Faculty of Computer and IT Sciences, University of Sumatera Indonesia

Saib Suwilo, Faculty of Computer and IT Sciences, University of Sumatera Indonesia

Needs analysis whose main focus is in the development of SPK is how to find out the needs of users (users) with the purpose of supporting data, for the process of answering the purpose of data users by using existing data and supporting external data in order to satisfy users.

The data that will be processed in this study is the problem of planning and managing the potential of natural resources, namely large-scale data, and contains uncertainty. So that the model that has been delivered previously is still not suitable for large-scale management. One approach to completing the optimization model which includes large scale and the uncertainty in the parameters is to use data driven (Wang et al., 2014). The results of the implementation of a data driven optimization approach in planning the management of resource potential so that the Charakter Variable Model of Decision on Regional Potential is obtained by Using Data Driven case studies of Aceh Province, Bireuen District, July District.

\subsection{Formulation of the problem}

1. Data and information about the potential of regions spread across various regions in Aceh province so that many interested parties, especially decision makers, have difficulty in obtaining data. Based on these conditions, a data driven approach model is needed for planning management of natural resources in the province of Aceh.

2. There needs to be an effort in optimizing the potential of resources in an integrated manner in supporting the improvement of economic development in the province of Aceh in order to realize community welfare

\subsection{Scope of problem}

So that this research can be focused on the problems that want to be resolved, the researchers limit the problems to be solved in this study are as follows:

1. The model used includes large-scale data that is using data driven that has been installed at www.SiAgam.web.id 2. Mathematical model of the linear programing method 3. The data used in this study is data on the potential of the area in the Kabuapten Bireuen Aceh province in July

\subsection{Research purposes}

The purpose of this study is to implement a data driven model approach in integrated source management planning, resulting in a Charakter Variable Model Determining Regional Potential Decisions Using Data Driven in decision making related to planning policies and managing natural resource potential. 


\subsection{Benefits of research.}

The benefit of the research is to produce a model with a data driven approach in planning integrated management potential in Aceh Province.

\section{REVIEW OF LITERATURE}

\subsection{Literature Review}

The Concept of Decision Support Systems was introduced around the 1970s. At that time the DSS was still in the process of Research and Development. While the application extensively began in approximately the late 1980s and early 1990s. And in the future DSS will continue to develop and require various improvements and improvements that are tailored to the needs and development of information technology. Among the DSS developments that will occur in the future, follow aspects: integrated architecture, connectivity, document data and intelligence.

\subsection{Decision Modeling}

Even the advantages of a simple linear model based on human intuitive considerations show that one way to improve the quality of decisions is to decipher decision problems into simple components that are well defined and well understood. Studying complex systems built from such components can be helped by formal and theoretical techniques.

The process of decomposition and formalization of a problem is often called modeling. Modeling amounts to finding abstract representations of real-world systems that simplify and assume as much as possible about the system, and while maintaining important system relationships, eliminate unnecessary details. Building models of decision problems, contrary to reasoning about problems holistically, allows the application of scientific knowledge that can be transferred through various problems and often throughout the region. This makes it possible to analyze, explain, and argue about decision problems.

The desire to improve human decision making motivates the development of various modeling tools in economic disciplines, operations research, decision theory, decision analysis, and statistics. In each of these modeling tools, knowledge of a system is represented by algebraic, logical or statistical variables. Interactions between these variables are expressed by logical equations or rules, which may be enhanced by an explicit representation of uncertainty. If the functional form of an interaction is unknown, it is sometimes described in pure probabilistic terms; for example with a conditional probability distribution.

Once the model has been formulated, various mathematical methods can be used to analyze it. Certainty-based decision making has been handled by economic research methods and operations, such as cash flow analysis, break-even analysis, scenario analysis, mathematical programming, inventory techniques, and various optimization algorithms for scheduling and logistics. Decision making under uncertainty improves the method above with a statistical approach, such as reliability analysis, simulation, and statistical decision making.

\subsection{Data-Driven Decision Support Systems}

Analyze a large amount of data that is available or incorporated in an organization's information system. This DSS helps with the decision making process by allowing users to obtain useful information from data stored in large databases. Many organizations or companies are starting to build this DSS to enable customers to obtain data from their websites or data from existing organizational information systems. Data Driven Example:

1. How many potential regions exist in each month in an area.

2. Comparing products to the sales plan every quarter and marketing area to the potential of each district / city in Aceh
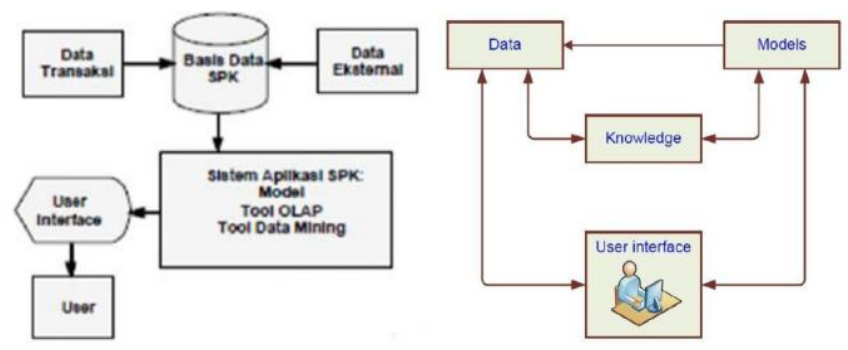

Figure 1: Concept of Determination of Charakter Variables

Decision of Regional Potential to Use Data Driven

2.4 Basic Components of Decision Support Systems

There are several basic components, in the System

Management Database, namely:

1. Database management system (DBMS). DBMS functions as a data bank for DSS. This stores a large amount of data that is relevant to the class of problems where the DSS has been designed and provides a logical data structure (in contrast to the physical data structure) by which users interact. The DBMS separates users from the physical aspects of database structure and processing. It must also be able to tell the user what type of data is available and how to access it.

2. Model-based management system (MBMS). The role of MBMS is similar to that of a DBMS. Its main function is to provide independence between the specific models used in DSS from the application that uses it. The purpose of MBMS is to transform data from DBMS into useful information in decision making. Because many of the problems that DSS users might face may not be structured, MBMS must also be able to help users in building a Decision Support System model.

\subsection{Stochastic Program Model}

The model proposed in this study is a sequential decision-making process in the presence of uncertainty at a finite time horizon. State the decision time horizon with $\mathrm{T}=$ $\{1, \ldots,|\mathrm{T}|\}$, assuming that information is given by the stochastic process \{\}$t\} t=1|T|$ which is defined in the probability space $(\Xi, F, P)$.

Decisions are based on information available at that time, that is, on the set of decisions that have been taken and on the outcomes of the random variables in the previous stage. If

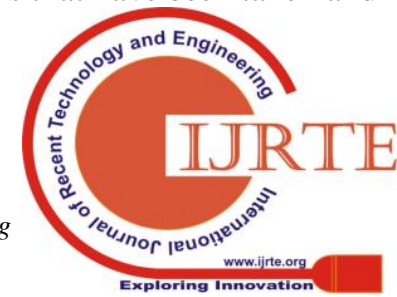


the vector of all decisions made from stage 1 to stage $t$ is shown by $\mathrm{xt}=(\mathrm{x} 1, \ldots, \mathrm{xt})$ and the random variable vector results over the same interval by $\xi \mathrm{t}=(\xi 1, \ldots, \xi \mathrm{t})$, then the model the double stage count stochastic program can be expressed as:

$$
\begin{gathered}
\operatorname{Min}\left\{c_{t}\left(\xi_{t}\right) x_{t}+Q_{t}\left(x_{t}\right) \mid \mathrm{W}_{t} x_{t} \leq h_{t}\left(\xi_{t}\right), x_{t} \in X_{t}\right. \\
Q_{t}\left(x_{t}\right)=E_{\xi}{ }_{t}{ }^{\xi} \min \left\{c_{t+1}\left(\xi_{t+1}\right) x_{t+1}+Q\left(x_{t+1}\right) ;\right. \\
\left.{ }^{T} t+1{ }^{(\xi} t+1\right) x_{t}+{ }^{t} t+1{ }^{x} t+1 \leq h_{t+1}\left(\xi_{t+1}\right), x_{t+1} \in X t+1
\end{gathered}
$$

For $\mathrm{t}=1, \ldots,|\mathrm{T}|-1$, with $\mathrm{Q}|\mathrm{T}| \equiv 0$. It is assumed that $\xi 1$ is known at time $\mathrm{t}=1$ and $\mathrm{E} \xi \mathrm{t}+1 \mid \xi \mathrm{t}$ expresses the expectation of the distribution of $\xi t+1$ which is required for the observation $\xi$ t. For all realization $\xi$ and time stages, it is assumed that $\mathrm{Tt}(\xi \mathrm{t}), \mathrm{Wt}$, ct $(\xi \mathrm{t}), \mathrm{ht}(\xi \mathrm{t})$ are rational matrices and vectors with certain dimensions. The Xt set states the requirement that some or all decision variables be counted. It is assumed that the expectations that define Qt are finite for any policy xt.

In this study, it is assumed that random vectors $\xi$ have finite support; namely $\Xi=(\xi 1, \ldots, \xi \mathrm{r})$ with probability $\mathrm{p} 1, \ldots .$. pr. This hypothesis results in uncertainty can be expressed by the

scenario. A scenario is the realization of a random variable (c $(\xi), \mathrm{h}(\xi), \mathrm{T}(\xi))$ which is related to an elementary event $\xi \varepsilon \Xi$

\section{RESEARCH METHODS}

\subsection{Methodology of Research Implementation}

\subsubsection{Preparation Before Discovery Workshop Data}

Before implementing the Discovery Workshop Data, please note the following:

1. Ensure that a village operator team has been formed which consists of 3 components: the functions of the legal \& policy fields, the functions of the information technology sector, and the functions of the communication sector

2. There has been a commitment from the village leadership to implement the Amgam and start the Discovery Workshop Data. In addition, the siAgam team has at least conducted informal meetings beforehand with the Satker / village who will be participants of the Data Discovery Workshop (DDW) and have provided some information regarding what is the security and benefits.

\subsubsection{Discovery Workshop Data}

1. Become an arena for inventorying the conditions of internal data (what data is produced in each hamlet / keplor / work unit and what data is needed).

2 Become a place of interaction between the Work Unit (Satker) / village and the siAgam team to communicate ideas and problems related to the One Data movement.

3. Produce a DRP (Data Release Plan) which is a reference for the SiAgam team to carry out data management in the portal www.SiAgam.web.id

\subsection{Steps in conducting Discovery Workshop Data}

Data Discovery Workshop (DDW) consists of 4 main stages. In this section, the steps that need to be taken in each stage will be described.

1. Planning Phase The www.siAgam.web.id team will meet in advance with the liaison officer and his team to discuss the following:

2. Any Satker that will participate in DDW.

3. Determine the time to carry out DDW template distribution and explanation regarding its filling to the village Satker.

4. Set a schedule for face-to-face meetings between the www.siAgam.web.id team and the Regional / Village team

5. Establish a deadline for completing the DRP (Data Release Plan) prepared based on the DDW template that has been filled in by the Working Unit and verified by the www.siAgam.web.id team

This section explains some of the things that need to be considered by the village in carrying out the Satu Data initiative www.siAgam.web.id. The following are the stages of implementation on the data driven provider side:

This section explains some of the things that need to be considered by the village in carrying out the Satu Data initiative www.siAgam.web.id. The following are the stages of implementation on the data driven provider side:
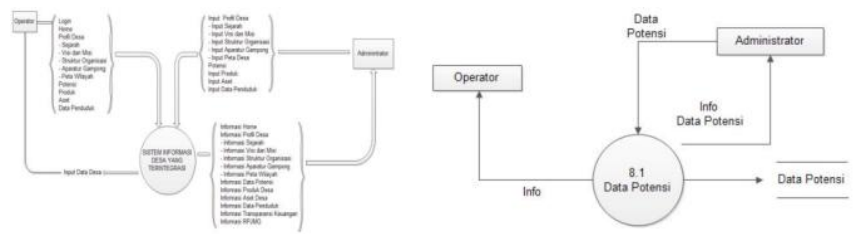

Figure 2: Process of Designing Potential Data for Determination of Charakter Variables Decision of Regional Potential to Use Data Driven

\subsection{Commitments of Agencies / Villages}

Institutional commitment is indicated by a statement of willingness to join the portal www.siAgam.web.id related institution (village). After that, it continued with the appointment of village operator officials, who had the task:

1. Coordinate internally for the implementation of the respective village web.

2. Working with the siAgam team to identify and formulate data governance reform policies in the villages of each region

3. Providing data on an ongoing basis in the web www.siAgam.web.id in accordance with the principles of Open Data.

4. Respond to requests and / or other questions from users relating to data and encourage active use of data. 


\subsection{Data-Driven: Uncertainty Decision Making}

To present a strong framework in mathematical terms, we closely follow Bertsimas and Sim and consider linear programming problems:

$$
\begin{aligned}
& \min c^{\prime} x \\
& \text { s.t. } A x \geq b, \\
& x X
\end{aligned}
$$

where uncertainty is assumed without losing generality only to influence the drag coefficients $\mathrm{A}$ and $\mathrm{X}$ are polyhedrons (not subject to uncertainty). Problem (1) appears in various settings; For example, it can be interpreted as a production planning problem where the decision maker must buy raw materials to minimize costs while meeting the demand for each product, despite uncertainty about machine productivity. Note that the problem with uncertainty in the cost of vector $\mathrm{c}$ and the right side $\mathrm{b}$ can be immediately reformulated as:

$$
\begin{aligned}
& \min Z \\
& \text { s.t. } Z-c^{\prime} x \geq 0 \\
& \text { Ax }- \text { by } \geq 0
\end{aligned}
$$

$\mathrm{x} X, \mathrm{y}=1$

\section{RESULTS}

\subsection{Results of the Research Implementation Determination of the Charakter Variable Model Decision of Regional Potential to Use Data Driven}

The stages of implementation are the stages in which data driven applications with the Charakter Variable Model Determination of Regional Potential Decisions that have been designed and built and then tested for feasibility are subsequently operated accordingly according to their functions and feasibility to be used by parties in need to realize the expected application and that has been designed. The choice of a programming language is a very important initial task before building a program. Integrated Village Information System Based on Android in July Subdistrict which has been built based on Android, the researcher chooses the programming language used is PHP (PHP Hypertext Processor), with several reasons and considerations as follows:

The program script for the SDA potential input page can be seen below!

<script> confirmdelete (delUrl) function if (confirm ("Are you sure you want to delete?")) \{document.location = delUrl; \}) </ script $><$ ? php session_start (); if (empty (\$_SESSION ['username']) AND empty (\$_SESSION ['passuser'])) \{ echo $"\langle\mathrm{p}\rangle\langle\mathrm{b}\rangle$ MODULE HAS NOT HAD OR NOT COMPLETE $</$ b $></$ p $>$ "; else

$n$

\section{$\left\{\right.$ s.t.ai $x-\Gamma_{i} p_{i}-\sum q_{i j} \geq b_{i}, \forall i$ Model Variabel Charakter Data Driven}

$$
j=1
$$

\{Charakter Data Driven Variable Model\$ check = user_akses $(\$$ _ GET [module], \$ _ SESSION [users_group]); if ( $\$$ check $==1$ OR $\$$ _SESSION [users_group] $==1\{\$$ action $=$ "module $/$ mod_potensi_sda $/$ Aksi_potensi_sda.php"; switch (\$_GET [act]) \{default:?> $<$ div class $=$ "panel -info $"><$ div class $=$ " panels $"><$ h6 class $=$ " panel-title "style $=$ " color: \#ffffff " $>$ DATA POTENTIAL
NATURAL RESOURCES </ h6> <div class = 'coll pull-right 'style $=$ ' padding-

top: 0px; padding-right: 2px; '> <a data-toggle="modal" role="button" href="?module=potensi_sda\&act=add"> $<$ button class $=$ 'btn-warning pull-right' type $=$ 'button' $\rangle\langle$ i class = 'icon-plus' $\rangle\langle/ \mathrm{i}\rangle$ ADD $</$ button $>\langle/$ a $\rangle\langle/ \operatorname{div}\rangle</$ div $>\langle$ div class $=$ "panel-body" style = "padding: 0px;" $>\langle\operatorname{div}$ class $=$ "block" $\rangle\langle\operatorname{div}$ class $=$ "datatable" $\rangle\langle\operatorname{div}$ class $=$ "table-responsive" > <table class = "table table- striped table-bordered table-hover "id =" table_general "style =" border-left: 0px; border-right: 0px; " $>\langle$ thead $\rangle\langle$ tr $\rangle\langle$ th $\rangle$ No. $</$ th $><$ th $>$ Potential Types SDA $</$ th $><$ th $>$ Potential Name $</$ th $\rangle<$ th $>$ Information $</$ th $\rangle<$ th $>$ Year $</$ th $\rangle\langle$ th $\rangle$ $\#</$ th $>$ no $=1$; $\$$ query = mysql_query ("SELECT * FROM pola_sdaWHEREvillage_id $=\$-$ SESSION [village_id]'"); while ( $\$ \mathrm{r}=$ mysql_fetch_array (\$ query)) $\{\$$ type $=$ mysql_fetch_array (mysql_query $($ "SELECT $*$ FROM Jenis_potensi_sda WHERE id = '\$ r [id_type_potensi_sda] '"));

\subsection{Main appearance of administrative information systems}

In making the Charakter Variable Model Determination of Regional Potential Decisions Using Data Driven District of July Bireuen District, researchers used a MySQL database integrated in the XAMPP 1.8.1 application because all table creation in the database was done by design-view using the default PhpMyAdmin editor tool from the XAMPP v3 application .1.0 3.1.0

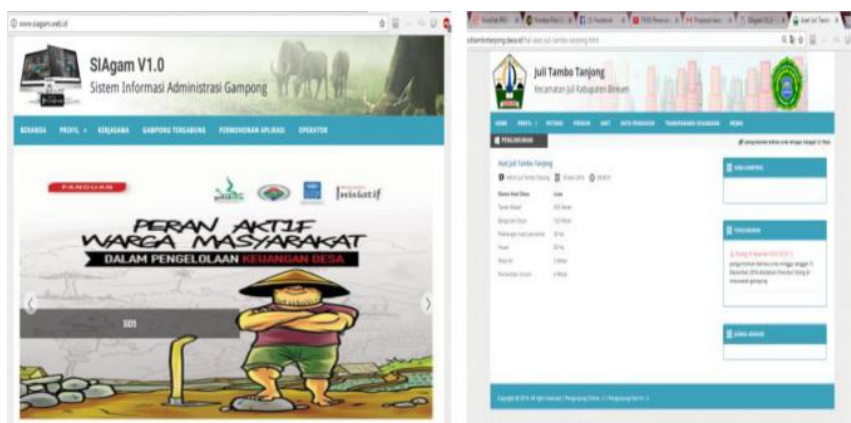

Figure 3: Implementation of a system for inputting potential profile data in the regions

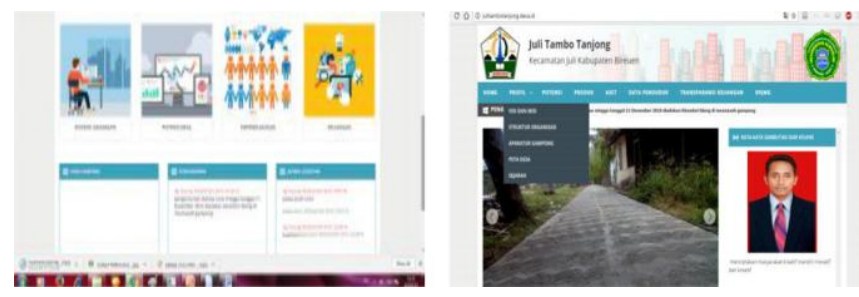

Figure 4: Implementation of the data input process system Charakter Determination Variable Decision of Regional Potential to Use Data Driven

\subsection{Interface Implementation}

Implementation of the interface is done with a webpage with PHP extension. Each page in the program file software written with PHP extension. The following is the implementation of the interface page of the Integrated Village Information System application in the July District of Bireuen District. 


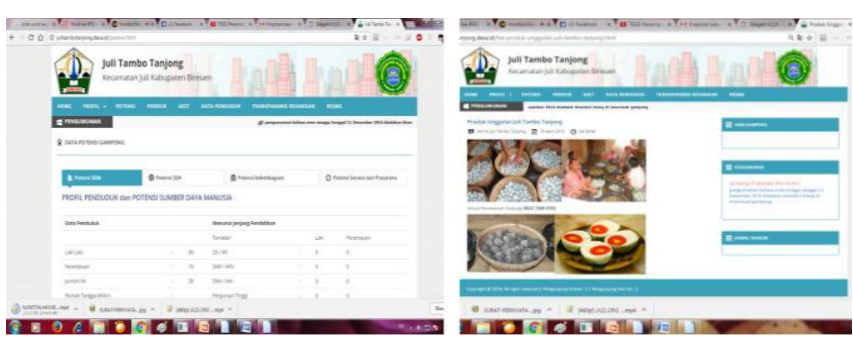

Figure 5: Display of Regional Potential Charakter Variable Decision Making Model Using Data Driven

\subsection{Display of Information System Main Menu}

In this Integrated Village Information System there are several interconnected villages which can be logged by each admin, below is the main menu display Information System Charakter Variable Model Determination of Decision Potential Areas Using Data Driven
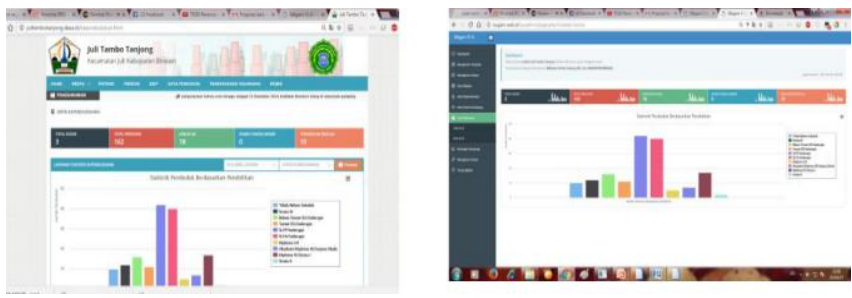

Figure 6: Graph data display of potential Charakter Variable Decision Making Model Regional Potential to Use Data Driven

\subsection{Implementation of Programming Languages Used}

The choice of programming language is a very important initial task before building a potential data program Charakter Variable Model Determination of Regional Potential Decisions Using Data Driven in July District Bireuen District which has been built based on Android, the researcher chose the programming language used is PHP (PHP Hypertext Processor), with several reasons and considerations as follows:

1. No browser compatibility or must use a certain browser because the server will work on the PHP script.

2. Freeware means that it can be distributed freely.

3. Having the ability to connect to various kinds of databases such as: MySQL, PostgreSQL, Oracle, dBase, Sybase, and several other advantages.

\section{CONCLUSION AND RECOMMENDATIONS}

The results of the study obtained Charakter Variable Model Determination of Regional Potential Decisions Using Data Driven which can already be applied for planning the management of natural resources potential, namely agriculture, plantations and fisheries optimally in Aceh province.

This Charakter Variable Model is also one of the efforts that can be used by the government in optimizing the potential of natural resources in an integrated manner in supporting the improvement of economic development in Aceh Province so that the realization of community welfare.

\section{SUGGESTIONS}

Further research needs dynamic data to include variable data from the Meteorology and Giophysics Agency (BMKG) both Charakter, Date, and Integer Variables.

\section{REFERENCES}

1. Chen, Y., X. Li, X. Liu, and Y. L. Liu. 2010. “An Agent-based Model for Optimal Land Allocation (AgentLA) with a Contiguity Constraint." International Journal of Geographical Information Science 24:1269-88.

2. Daniel Kahneman, Paul Slovic, and Amos Tversky, editors. Judgment Under Uncertainty:Heuristics and Biases. Cambridge University Press, Cambridge, 1982.

3. Drudzel, M. J., Flynn, R. R. 2002. Decision Support Systems. Encyclopedia of Library and Information Science, Second Edition, Allen Kent (ed.), New York: Marcel Dekker, Inc.

4. Efrain Turban, Ramesh Sharda, Dursun Delen, Sistem Penunjang Keputusan Dan Informasi Eksekutif. diterjemahkan Bayu Indrayana Program Pascasarjana 2013. IPB Bogor.

5. Ligmann-Zielinska, A. 2017. "Spatial Optimization." The InternationalEncyclopedia of Geography: 1-6. http://onlinelibrary.wiley.com/doi/10.1002/9781118786352.wbieg0156 /

abstract;jsessionid=BB7FA4B38B8D8FB2234B607D22178806.f04t0 2

6. Robyn M. Dawes. 1988. Rational Choice in an Uncertain World. Hartcourt Brace Jovanovich, Publishers.

7. Sante', I., N. Pacurucu, M. Boullo'n, A. M. Garci'a, and D. Miranda 2016. "An Open Source GIS-based Planning Support System: Application to the Land Use Plan of La Troncal, Ecuador." Transactions in GIS 20:976-90.

8. Sarkar, S., J. S. Dyer, C. Margules, M.Ciarleglio,N. Kemp, G. Wong, D. Juhn, and J.Supriatna. 2017."Developing an Objectives Hierarchy for Multicriteria Decisionson Land Use Options, with a Case Study of Biodiversity Conservation and Forestry Production from Papua, Indonesia." Environment and Planning B: Urban Analytics and City Science 44:464-85.

9. Shaparev, N., Yakubalik, O. 2016. Usage of web mapping systems and service for information support of regional management. MATEC Web of Conferences 79, 01081

10. Taufiq, Maryana, M.Daud Nurdin. Model Informasi Desa Terintegrasi Berbasis Android. Unimal Pres 2017 Lhokseumawe.

11. Taufiq Modul Aplikatif Sistem Informasi Adminitasi Gampong (SiAgam V.1) Penerbit Umuslim 2017 Bireuen.

12. Tong, D., and A. T. Murray. 2012. "Spatial Optimization in Geography." Annals of the Association of American Geographers 102:1290-309.

13. Wang, Z., Glynn, P. W., Ye, Y. 2014. Likelihood robust optimization for data-driven problems. arXiv: $1307.6279 \mathrm{v} 3$ [math.OC].

14. Yao, J., Zhang, X., Murray, A. T. 2017. Spatial optimization for land-use allocation: Accounting for sustainability concerens. International Regional Science Review, 1-22.

15. www.siagam.web.id 